\title{
Price competition under universal service obligations
}

\author{
Axel Gautier* and Xavier Wauthy ${ }^{\dagger}$
}

\begin{abstract}
In industries like telecom, postal services or energy provision, universal service obligations (uniform price and universal coverage) are often imposed on one market participant. Universal service obligations are likely to alter firms' strategic behavior in such competitive markets. In the present paper, we show that, depending on the entrant's market coverage and the degree of product differentiation, the Nash equilibrium in prices involves either pure or mixed strategies. We show that the pure strategy market sharing equilibrium, as identified by Valletti, Hoernig, and Barros (2002), defines a lower bound on the level of equilibrium prices.
\end{abstract}

Key words universal service, uniform price, universal coverage

JEL classification L13, L51

Accepted 30 April 2010

\section{Introduction}

Universal service obligations go along with the process of deregulation at work in most of the former public monopoly industries. Several important questions have been addressed in the published literature. How should we define universal service obligations? What are the costs of universal service obligations (Panzar 2000) and how should they be financed (Choné, Flochel, and Perrot 2002; Mirabel, Poudou, and Roland 2009)? Which firms should be subject to universal service obligations (Hoernig 2006)? In the present paper, we focus on the implications of universal service obligations for price competition in a deregulated industry.

Valletti, Hoernig, and Barros (2002) underline the fact that whenever universal service obligations involve a constraint of uniform pricing, this constraint creates a strategic link between otherwise segmented markets and induces a less aggressive pricing pattern by the incumbent. Because prices are strategic complements, equilibrium prices tend to increase overall and this, in turn, is likely to affect the extent of market coverage by incoming firms.

* CREPP, HEC-Université de Liège, Belgium and Center for Operations Research and Econometrics, Université Catholique de Louvain, Louvain-la-Neure, Belgium. Email: agautier@ulg.ac.be

$\dagger$ CEREC, Facultés universitaires St Louis, Brussels, Belgium and Center for Operations Research and Econometrics, Université Catholique de Louvain, Louvain-la-Neure, Belgium.

We are grateful to Nicolas Boccard, Jean-Christophe Poudou, Tommaso Valletti and an anonymous referee for their useful comments. 
Anton, Vander Weide, and Vettas (2002) establish a comparable result under quantity competition.

The argument is best summarized as follows. Think of a reference industry consisting of a collection of segmented submarkets (typically, the industry for postal services, with submarkets corresponding to delivery routes in different geographical areas). Suppose then that the historical operator is challenged by an entrant on a limited number of submarkets. Assume further that universal service obligations constraint the incumbent's behavior: it must offer its services in all submarkets at a uniform price. At the price competition stage, the incumbent's behavior is affected by the extent of the entrant's market coverage. If the entrant is a low scale competitor, the incumbent firm is better off setting a price close to the monopoly price. In this case, it enjoys near monopoly profits on the (relatively numerous) protected markets but possibly sells very little, or nothing, on the contested markets. If the entrant covers a larger set of submarkets, the incumbent is better off being more aggressive over the whole set of submarkets. In which case the profits lost on the protected markets are compensated by larger sales on the (relatively numerous) contested ones. Hence, by choosing the number of submarkets it challenges, the entrant controls the aggressiveness of the incumbent. Prices therefore decrease with the entrant's coverage (Valletti, Hoernig, and Barros 2002, lemma 1). For that reason, the entrant will strategically limit its entry scale.

The present paper builds on this line of argument but goes a step further. It is conceivable indeed that, under universal service obligations, the incumbent decides to withdraw on the protected markets where it can charge the monopoly price and collect the corresponding monopoly profits. This strategy is particularly attractive when competition is fierce on the contested markets (e.g. because products are close substitutes) and insulated markets are relatively numerous. However, this strategy proves to be quite difficult to sustain in equilibrium: if the incumbent 'retreats' on the insulated markets, the entrant is likely to price almost as a monopolist on the contested markets, which, in turn, is likely to trigger an aggressive response by the incumbent. The presence of universal service obligations therefore tends to destabilize price competition. Formally speaking, taking this strategy into account may destroy the pure strategy Nash equilibrium (Valletti, Hoernig, and Barros 2002; Hoernig 2002).

In this paper, we address precisely this point: we discuss the existence of the pure strategy Nash equilibrium in the price game when universal service obligations are imposed on one market participant. In a Hotelling setup, we characterize the price equilibrium under universal service obligations and identify the range of parameters for which a pure strategy or a mixed strategy equilibrium, respectively, exists. For a relatively low market coverage by the entrant, the equilibrium is a quasi-monopoly (pure strategy) equilibrium where the incumbent retreats on the insulated markets and the entrant monopolizes the contested markets with a limit price. For a relatively high market coverage, at equilibrium, the incumbent challenges the entrant on the whole set of contested markets with an aggressive price. Finally, for intermediate values of the entrant's coverage, the equilibrium is a mixed strategy one. Then, we characterize the optimal degree of market coverage by the entrant. In the Hotelling setup, the entrant covers fewer markets when universal services obligations are imposed on the incumbent. Moreover, optimal coverage is such that the relevant price equilibrium is either the mixed strategy or the quasi-monopoly equilibrium. Thus, universal 
service obligations unambiguously increase the price on the contested markets while they do not necessarily lead to a price below the monopoly price in the protected markets. Finally, in a more general setup, we derive general conditions on market coverage and the degree of product differentiation for the existence of the pure strategy market-sharing equilibrium considered by Valletti, Hoernig, and Barros (2002).

\section{Price competition without universal service obligations}

There is a continuum of identical local markets indexed by $j, j \in[0, N]$. Universal service obligations consist of two constraints: a universal coverage constraint and a uniform price constraint. If universal service obligations are imposed on the incumbent, firm $I$, this firm must serve all the markets at a uniform price, $p_{i}$. The entrant, firm $E$, is not constrained by universal service obligations and serves a subset of the $N$ markets at price $p_{e}$. Let $n_{e}$ denote the index of the last market firm $E$ has decided to compete in. The complete set of markets can, therefore, be decomposed into two subsets: the set $\left[0, n_{e}\right]$ of contested markets and the complement $\left.] n_{e}, N\right]$ of insulated ones. Serving a market $j \in[0, N]$ involves a fixed cost $g(j) \geq 0$. Markets are ordered in such a way that $g^{\prime}(j) \geq 0$. All operating costs are normalized to zero.

Firm $I$ and $E$ sell differentiated products and we rely on the linear version of the Hotelling model to formalize differentiation. ${ }^{1}$ In each market $j \in[0, N]$, consumer's type $x$ are uniformly distributed in the $[0,1]$ interval according to their idiosyncratic taste. The indirect utility of a consumer's type $x$, buying a product $k$ is given by:

$$
U(x)=S-t d(x, k)-p,
$$

where $d(x, k)$ is a measure of the distance between the product's characteristic and type $x$ 's ideal product. If the consumer does not buy any product, his or her utility is defined as $U(x)=0$. Incidentally, this means either that consumers cannot turn to alternative markets where a comparable service would be offered, or that if they can, they are charged a price that leaves them no surplus. The incumbent offers a product with characteristic $x=0$ and the entrant a product with type $x=1$.

In each market, the monopoly payoff is given by $\pi^{M}=p \frac{S-p}{t}$ and this expression is maximized for $p=\frac{S}{2}$. We shall assume that $\frac{S}{t}>2$. As a result, the monopoly price on each market is a corner solution: $p^{m}=S-t$. The monopoly price leaves the consumer located at a distance 1 from the monopolist indifferent between buying and not buying. This assumption is perfectly in line with the literature on Hotelling competition, which most often assumes full coverage by assuming that $S$ is large enough. ${ }^{2}$

On the contested markets, standard Hotelling competition takes place, taking $n_{e}>0$ as given. Given consumers' preferences, we may identify the indifferent consumer,

1 In Section 4 we extend the analysis to a more general model of product differentiation.

2 Notice that this assumption of monopoly market coverage means that no market expansion effect is expected as a result of competition. All of the market shares gained by the entrant are taken from the incumbent (the displacement ratio is equal to 1). As shown hereafter, this particular feature of the model reinforces the strategic value attached by the entrant to a voluntary limitation of the market coverage. 
denoted by $\tilde{x}$, who separates the firms' market shares. By definition, he or she solves $S-t \tilde{x}-p_{i}=S-t(1-\tilde{x})-p_{e}$. Formally, we obtain

$$
\tilde{x}=\frac{t-p_{i}+p_{e}}{2 t} .
$$

Demands addressed to Firms $I$ and $E$ are then defined as follows:

$$
\begin{aligned}
& x_{i}^{D}\left(p_{i}, p_{e}\right)= \begin{cases}0 & \text { iff } p_{i} \geq p_{e}+t \\
\tilde{x} & \text { iff } p_{i} \in\left[p_{e}-t, p_{e}+t\right] \\
1 & \text { iff } p_{i} \leq p_{e}-t\end{cases} \\
& x_{e}^{D}\left(p_{i}, p_{e}\right)= \begin{cases}0 & \text { iff } p_{e} \geq p_{i}+t \\
1-\tilde{x} & \text { iff } p_{e} \in\left[p_{i}-t, p_{i}+t\right] . \\
1 & \text { iff } p_{e} \leq p_{i}-t\end{cases}
\end{aligned}
$$

$x_{k}^{D}($.$) denotes the duopoly demand addressed to firm k$ in a contested market and $\pi_{k}^{D}($. is the corresponding operating profit. Similarly, $x^{M}$ and $\pi^{M}($.$) are the monopoly demand$ and profit on a monopolized market. Finally, $\Pi_{k}($.$) is the total operating profit of firm k$ over the whole set of markets: $\Pi_{i}=n_{e} \pi_{i}^{D}+\left(N-n_{e}\right) \pi^{M}$ and $\Pi_{e}=n_{e} \pi_{e}^{D}$. To obtain the final payoff of firm $k$, we must substract from $\Pi_{k}$ the fixed cost of serving markets.

When there are no universal service obligations, firms' optimal behavior can be characterized independently on each local market. We only have to distinguish between contested and insulated markets, depending on whether the entrant challenges the incumbent. Equilibrium prices on the contested markets solve:

$$
\begin{aligned}
& \phi_{i}^{1}\left(p_{e}\right) \equiv \underset{p_{i}}{\operatorname{argmax}} p_{i} \tilde{x}=\frac{p_{e}+t}{2} \\
& \phi_{e}^{1}\left(p_{i}\right) \equiv \underset{p_{e}}{\operatorname{argmax}} p_{e}(1-\tilde{x})=\frac{p_{i}+t}{2} .
\end{aligned}
$$

Equilibrium prices $p_{i}^{1 *}=t=p_{e}^{1 *}$ solve (3) and (4). Without universal service obligations, the Nash equilibrium is, therefore, characterized as follows:

Proposition 1 When the incumbent is not subject to universal service obligations,

(i) Equilibrium prices in the contested markets are given by $p_{i}^{1 *}=t=p_{e}^{1 *}$.

(ii) The incumbent charges the monopoly price $p^{m}=S-t$ on the insulated markets.

(iii) The entrant's optimal coverage is given by: $n_{e}^{*}=\operatorname{Min}\left[g^{-1}\left(\frac{t}{2}\right), N\right]$. The incumbent's optimal coverage is $n_{i}^{*}=\operatorname{Min}\left[g^{-1}(S-t), N\right]$.

Notice that whenever $g(j)=0 \forall j \in[0, N]$, both firms cover all markets. ${ }^{3}$

3 Imposing universal service obligations is relevant when there are markets that otherwise would not be served, that is, when there are unprofitable markets: for some $j \in[0, N], \nexists p$ such that $\pi^{M}(p)-g(j) \geq 0$. 


\section{Price competition with universal service obligations}

Whenever the incumbent is not subject to universal service obligations, its profit is additively separable between the $n_{e}$ contested markets and the $N-n_{e}$ insulated ones. This explains why optimal prices do not depend on market coverage in this case. However, this property does not hold under universal service obligations. The uniform pricing constraint creates a strategic link between the two types of markets because increasing market shares in the contested segment by decreasing the price involves an opportunity cost corresponding to those profits that are lost through this price decrease on the insulated segment. The characterization of a Nash equilibrium in prices is more involved because of this trade-off.

Under universal service obligations, the incumbent faces a positive demand on the contested markets only if $p_{i} \leq p_{e}+t$. Therefore, the operating profit of firm $I$ is defined as follows:

$$
\Pi_{i}\left(p_{i}, p_{e}\right)= \begin{cases}\left(N-n_{e}\right) p_{i} & \text { if } p_{i} \geq p_{e}+t \\ \left(N-n_{e}\right) p_{i}+n_{e} p_{i} \tilde{x} & \text { if } p_{i} \leq p_{e}+t\end{cases}
$$

Given $p_{e}$, the incumbent has two options: it may either set a relatively high price such that it is actually not active on the contested markets and focuses on the protected ones, or it names an aggressive price and shares contested markets with the entrant. To characterize the incumbent's best reply, we need to consider two different strategy profiles, corresponding to the two branches of the monopoly profit (Equation 5) and compare the resulting payoffs to formally identify the relevant best reply.

Lemma 1 The best reply correspondence of the incumbent is given by the following equation:

$$
B R_{i}\left(p_{e}\right)= \begin{cases}p^{m}=S-t & \text { if } p_{e} \leq \tilde{p}_{e} \\ \phi_{i}\left(p_{e}\right)=\frac{p_{e}+t}{2}+t\left(\frac{N}{n_{e}}-1\right) & \text { if } p_{e} \geq \tilde{p}_{e}\end{cases}
$$

with $\tilde{p}_{e}=1-\frac{2 N}{n_{e}}+\frac{2 \sqrt{2} \sqrt{\left(N-n_{e}\right) n_{e}} \sqrt{S-t}}{n_{e}}$.

Proof: Notice that the payoff function in the lower branch of (5) is not necessarily concave in own price. There are two candidate price best replies for the incumbent. The monopoly price $p^{m}$ defined along the first branch of (5) is a first candidate. It ensures the incumbent to benefit at least from the monopoly profit on the $N-n_{e}$ insulated markets. Let us define this strategy as the security strategy, because it defines the lowest payoff that the incumbent can guarantee to itself, whatever the entrant's strategy; that is, its MinMax payoff. The second candidate, which we call the aggressive price maximizes profits along the second branch of (5). Let us denote this candidate by $\phi_{i}\left(p_{e}\right)$. By definition, it is defined by $\operatorname{argmax}_{p_{i}}\left(N-n_{e}\right) p_{i}+n_{e} p_{i} \tilde{x}$. Solving the first-order condition along the second branch of (5) for $p_{i}$ we obtain:

$$
\phi_{i}\left(p_{e}\right)=\frac{p_{e}+t}{2}+t\left(\frac{N}{n_{e}}-1\right) .
$$


It then remains to compare the profit obtained by the incumbent, given $p_{e}$, when playing either of these two best reply candidates. Intuitively, against a high price from the entrant, fighting on the contested markets is not too costly in terms of lost monopoly revenues on the protected markets, whereas the contrary prevails if the entrant's price is low. Computations indicate that there exists a critical price $\tilde{p}_{e}$ below which the incumbent prefers to retire on the protected markets and set the monopoly price, and above which the incumbent sells on both contested and protected markets at a uniform price. By definition, such a price, $\tilde{p}_{e}$, ensures that when the incumbent optimally replies to that price along the second branch of (5) (i.e. the incumbent replies aggressively), the resulting payoff is identical to the payoff obtained when playing the security strategy (i.e. the monopoly payoff aggregated over the $N-n_{e}$ insulated markets). Formally, $\tilde{p}_{e}$ solves

$$
n_{e} \pi_{i}^{D}\left(\phi_{i}, \tilde{p}_{e}\right)+\left(N-n_{e}\right) \pi^{M}\left(\phi_{i}\right)=\left(N-n_{e}\right) \pi^{M}\left(p^{m}\right) .
$$

Direct computations then yield

$$
\tilde{p}_{e}=1-\frac{2 N}{n_{e}}+\frac{2 \sqrt{2} \sqrt{\left(N-n_{e}\right) n_{e}} \sqrt{S-t}}{n_{e}} .
$$

Three remarks are in order at this stage. First, in subgames where the coverage is close to zero, the price defined by $\phi_{i}($.$) tends to increase exponentially. In this case, consumers$ stop buying and the demand is no longer equal to $\tilde{x}$. Hence, the corresponding best reply must be computed as the solution to $U(\tilde{x})=0$, which is relevant against the highest values of $p_{e}$. Second, whenever the entrant does not cover all markets $\left(n_{e}<N\right)$, the incumbent is less aggressive on the contested markets compared to the case without universal service obligations: $\phi_{i}()>.\phi_{i}^{1}\left(\right.$.). Moreover, $\frac{\partial \phi_{i}}{\partial n_{e}}>0$. These results are well-known from Valletti, Hoernig, and Barros (2002). Finally, and more importantly, the best reply correspondence exhibits a downward jump at $\tilde{p}_{e}: \phi_{i}\left(\tilde{p}_{e}\right)<p^{m}$.

The profit realized by the entrant when it challenges $n_{e}$ markets is given by:

$$
\Pi_{e}\left(p_{i}, p_{e}\right)= \begin{cases}n_{e} p_{e} & \text { if } p_{e} \leq p_{i}-t \\ n_{e} p_{e}(1-\tilde{x}) & \text { if } p_{e} \geq p_{i}-t\end{cases}
$$

Because the incumbent may choose to set the monopoly price as an optimal strategy, we must consider the possibility that the entrant excludes the incumbent from the contested markets by setting a limit price. This price maximizes profits along the first branch of the above equation. Because the payoff is strictly increasing along this branch, we may define this limit price as:

$$
p_{e}^{L}\left(p_{i}\right)=p_{i}-t
$$

The entrant's optimal behavior is summarized in the following lemma:

Lemma 2 The best reply function of the entrant is given by the following equation:

$$
B R_{e}\left(p_{i}\right)=\operatorname{Max}\left[\phi_{e}^{1}\left(p_{i}\right), p_{e}^{L}\left(p_{i}\right)\right] .
$$




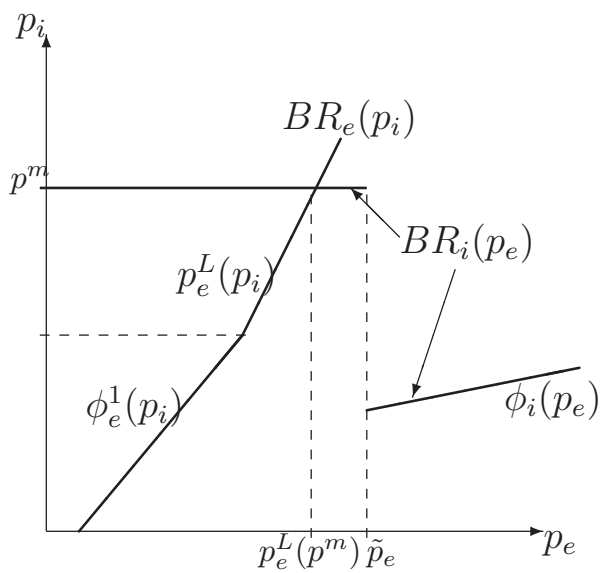

Figure 1 Quasi-monopoly pure strategy equilibrium.

PROOF: There are two best reply candidates for the entrant: the limit price $p_{e}^{L}\left(p_{i}\right)$ and the profit-maximizing price defined along the second branch of the profit function. This latter candidate is identical to the price maximizer without universal service obligations and is given by (4). Notice that the entrant's profit function is concave in own price; therefore, there exists a unique best reply that is defined by the maximum of the two candidates $p_{e}^{L}$ or $\phi_{e}^{1}($.$) .$

\subsection{Equilibrium analysis}

Depending on the entrant's coverage, there are three possible and mutually exclusive equilibrium configurations: two pure strategy equilibrium and a mixed strategy equilibrium. We consider each of them in turn.

Quasi-Monopoly Pure Strategy Equilibrium The first candidate is defined by $\left(p^{m}=S-t, p_{e}^{L}\left(p^{m}\right)=S-2 t\right)$. The incumbent monopolizes the protected markets and the entrant monopolizes the challenged markets with a limit price. This equilibrium is depicted in Figure 1. The entrant's best reply exhibits a kink for the pair of prices where the non-negativity constraint on $x_{i}^{D}($.) becomes binding. Our equilibrium candidate lies above this kink. A necessary condition for this candidate to be a valid one is that $\phi_{i}(S-2 t) \geq S-t$; that is, the best reply defined by (7) against $p_{e}=S-2 t$ is above the monopoly price. This condition is satisfied whenever $n_{e} \leq n_{e}^{-} \equiv \frac{2 t N}{S+t}$. A second necessary condition is that $\phi_{e}^{1}(S-t) \leq S-2 t$; that is, the entrant's best reply against $S-t$ is not defined by the interior solution. This condition is satisfied whenever $S \geq 4 t$. When these two conditions are satisfied, $(S-t, S-2 t)$ defines the unique Nash equilibrium. ${ }^{4}$

4 This equilibrium may exist because the monopoly price $p^{m}$ is a corner solution. 


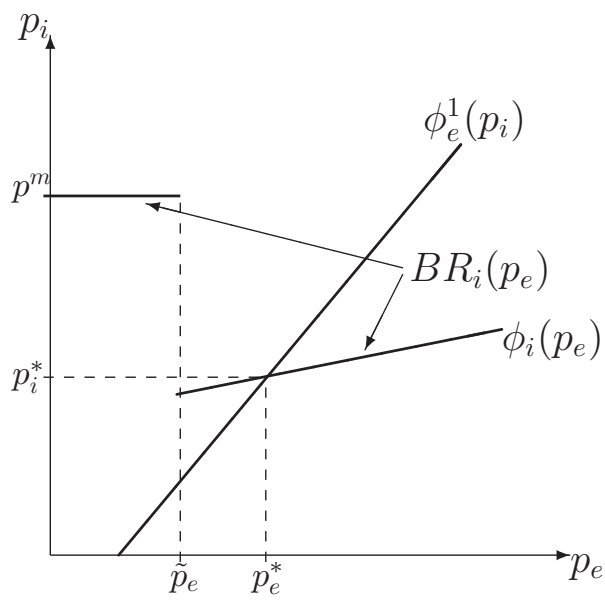

Figure 2 Market sharing pure strategy equilibrium.

Market Sharing Pure Strategy Equilibrium The second candidate equilibrium in pure strategies can be identified by solving the system $\left\{p_{i}=\phi_{i}\left(p_{e}\right), p_{e}=\phi_{e}^{1}\left(p_{i}\right)\right\}$. We obtain:

$$
\begin{aligned}
& p_{i}^{*}=\frac{t}{3}\left(\frac{4 N}{n_{e}}-1\right), \\
& p_{e}^{*}=\frac{t}{3}\left(\frac{2 N}{n_{e}}+1\right) .
\end{aligned}
$$

Such an equilibrium is depicted in Figure 2. For this equilibrium to exist, it is necessary that the downward jump in firm I's best reply, as identified in Lemma 1, takes place for a low value of $p_{e}$. More precisely, this equilibrium applies whenever $p_{e}^{*} \geq \tilde{p}_{e}$, as depicted in Figure 2. Formally, this inequality defines a critical number of local markets, $n_{e}^{+}$, above which the competitive pure strategy equilibrium exists. Computations indicate that $n_{e}^{+}$is defined as:

$$
n_{e}^{+}=\frac{2\left(6 \sqrt{3} \sqrt{N^{2}(S-t)(-3+3 S-t(7+t))}+N(9+18 S-t(18+t))\right)}{9+72 S+(-78+t) t},
$$

with $n_{e}^{-}<n_{e}^{+}$. An interesting feature of this equilibrium is that $p_{k}^{*}$ decrease with the entrant's coverage and converge to $p_{k}^{1 *}$ as the entrant reaches full coverage.

Mixed Strategy Equilibrium For intermediate values of $n_{e} \in\left[n_{e}^{-}, n_{e}^{+}\right]$no pure strategy equilibrium exists. However, a mixed strategy equilibrium exists because payoffs are continuous.

Referring to Figure 3, we observe that $p_{e}^{*}<\tilde{p}_{e}$. Therefore, there exists no intersection between the firms' best replies, hence no pure strategy equilibrium. There exists, however, one natural candidate, mixed strategy equilibrium to consider. Firm $I$, which has a discontinuous best reply, randomizes over two prices, which are the two possible values of $B R_{i}$ at 


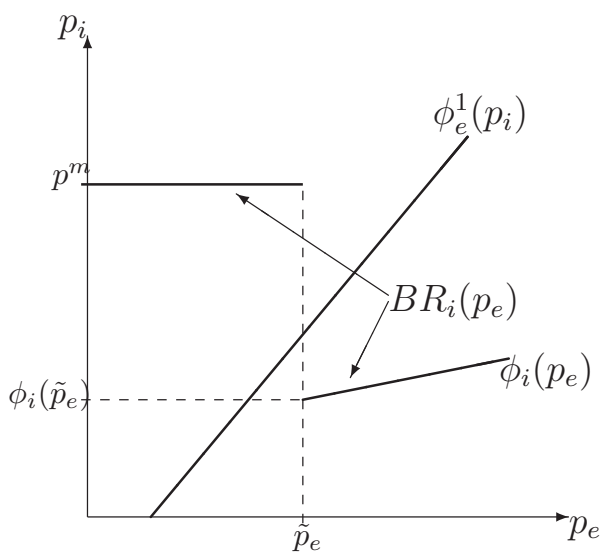

Figure 3 Mixed strategy equilibrium.

the point of discontinuity. That is, firm $I$ chooses $p^{m}$ with probability $\alpha$ and $\phi_{i}\left(\tilde{p}_{e}\right)$ with probability $(1-\alpha)$. The probability $\alpha$ is chosen to ensure that playing the pure strategy $\tilde{p}_{e}$ is indeed a best reply for firm $E .^{5}$ Formally, $\alpha$ is defined by:

$$
\underset{p_{e}}{\operatorname{argmax}} \alpha \pi_{e}^{D}\left(p^{m}, p_{e}\right)+(1-\alpha) \pi_{e}^{D}\left(\phi_{i}, p_{e}\right)=\tilde{p}_{e} .
$$

Summing up, we have established the following proposition:

Proposition 2 Under universal service obligations, one of the following mutually exclusive equilibrium applies:

- The incumbent sets the monopoly price $p^{m}$, while the entrant sets a limit price $p_{e}^{L}\left(p^{m}\right)$ such that it is the only active firm on the contested markets. This equilibrium prevails whenever $n_{e} \in\left[0, n_{e}^{-}\right]$.

- For intermediate values $n_{e} \in\left[n_{e}^{-}, n_{e}^{+}\right]$, a mixed strategy equilibrium prevails: the incumbent names $p^{m}$ with probability $\alpha$ (defined by Equation 13$)$ and $\phi_{i}\left(\tilde{p}_{e}\right)$ with probability $(1-\alpha)$; the entrant plays the pure strategy $\tilde{p}_{e}$.

- Whenever $n_{e} \in\left[n_{e}^{+}, N\right]$, a pure strategy equilibrium exists where the incumbent names $p_{i}^{*}$ and the entrant names $p_{e}^{*}$. Firms share the contested markets.

\subsection{Optimal coverage by the entrant}

Because they alter equilibrium prices in the contested markets, universal service obligations also affect the entrant's payoffs, hence entry behavior. From equilibrium payoffs in the pricing game, it is straightforward to show that the equilibrium prices and the profit

5 To the best of our knowledge, the structure of this equilibrium is analyzed first by Krishna (1989) and is developed further in various contexts. See, for instance, Boccard and Wauthy (2003) for an application in the context of a Hotelling model. 
obtained by the entrant in each covered market are weakly decreasing in $n_{e}$ (and strictly decreasing for $\left.n_{e} \geq n_{e}^{-}\right)$. Therefore, the entrant has strategic reasons to limit its market coverage (Valletti, Hoernig, and Barros 2002). The following proposition establishes that, when coverage is endogenous and when there are no fixed costs of serving markets, the optimal coverage is such that the resulting price equilibrium is the mixed strategy equilibrium. If serving markets is costly, it will decrease further the entrant's coverage. Hence, in our example where local markets are represented by a Hotelling line, the interior "market sharing" equilibrium is never the relevant one.

Proposition 3 (i) The optimal coverage by the entrant $n_{e}^{*}$ is smaller than $n_{e}^{+}$. (ii) If $g(j)=0 \forall j \in[0, N]$, then $n_{e}^{*} \in\left[n_{e}^{-}, n_{e}^{+}\right]$.

Proof: Consider first that $g(j)=0 \forall j \in[0, N]$. We have: (i) for $n_{e} \in\left[0, n_{e}^{-}\right]$, the entrant's profit $n_{e}(S-2 t)$ is strictly increasing in $n_{e}$; (ii) for $n_{e} \in\left[n_{e}^{+}, N\right]$, the entrant's profit $n_{e} p_{e}^{*}(1-\tilde{x})$ is strictly decreasing in $n_{e}$; and (iii) The entrant's payoff is continuous in $n_{e}$. In particular, we have $\lim _{n_{e} \rightarrow n_{e}^{+}} \alpha=0$ (because at $n_{e}^{+}, p_{e}^{*}=\tilde{p}_{e}$ ) and $\lim _{n_{e} \rightarrow n_{e}^{-}} \phi_{i}\left(\tilde{p}_{e}\right)=p^{m}$. Therefore, the highest payoff will be reached for $n_{e}$ in $\left[n_{e}^{-}, n_{e}^{+}\right]$. Finally, when market coverage is costly and $g^{\prime}(j)>0$, coverage will be reduced further.

Our findings can be illustrated with the help of a numerical example. Consider for instance that $N=1, S=5, t=1$ and $g(j)=0, \forall j$. Numerical computations yield the following outcomes: $n_{e}^{-} \simeq 0,33, n_{e}^{+} \simeq 0,83$ and $n_{e}^{*} \simeq 0$.45. In other words, the entrant covers approximately 45 percent of the markets. Because $g(j)=0, \forall j$, the entrant would have covered 100 percent of the markets without universal service obligations.

In the present setup, the strategic effect of limited coverage is particularly neat. When limiting its market coverage, the entrant relaxes price competition; this positively affects local profits and, therefore, possibly compensates for the smaller number of covered markets. However, the equilibrium price differential between the incumbent and the entrant also increases. Because the displacement ratio is equal to 1 (i.e. the market is fully covered), this implies that firm E's market share increases in all of the contested markets. This second effect clearly pushes incentives towards a more limited coverage.

\subsection{Price equilibrium and optimal coverage with and without universal service obligations}

In this section we compare the nature of equilibrium depending on whether universal service obligations apply or not. Universal service obligations change the nature of price competition because they create a strategic link between the markets that are contested by the entrant, $\left[0, n_{e}\right]$, and those that are shielded from competition, $\left.] n_{e}, N\right]$. This strategic link has the following consequences on the incumbent's pricing behavior. First, the incumbent has the option to withdraw from the protected market, leaving the contested markets to the entrant. Second, if it decides to compete on the whole set of markets, it is less aggressive in the price game because any price decrease that would induce higher profits in the contested markets goes along with a profit reduction in the protected ones. As a result, whatever the entrant's price, the incumbent's best reply necessarily involves a higher price under 
universal obligations than without them whenever the set of protected markets is nonempty (compare Equation 6 with Equation 4). As for the entrant, its best reply is invariant to the presence of universal service obligations, except for the fact that the entrant might use a limit price, and if it does so, its price is strictly higher with universal service obligations. Consequently, equilibrium prices on the contested markets must be higher under universal service obligations. This property is obviously satisfied in the mixed strategy equilibrium because in such an equilibrium the lower bound of the incumbent's price is precisely defined by $\phi_{i}\left(\tilde{p}_{e}\right)>\phi_{i}^{1}\left(\tilde{p}_{e}\right)$.

Summing up, if we compare the market outcome with and without universal service obligations, we can conclude that, with universal service obligations:

1. Prices are strictly higher on the contested markets.

2. Prices are not necessarily lower on the protected markets.

3. The incumbent has a higher coverage and the entrant may have a higher or a lower coverage.

The incumbent's higher coverage is a direct consequence of the universal coverage constraint. For the entrant, the impact of universal service obligations on coverage is actually twofold. The entrant realizes a higher profit on each covered market and this stimulates market expansion. At the same time, the entrant has strategic reasons to limit its coverage in order to maintain higher prices. The impact of universal service obligations on the entrant's coverage depends on the relative importance of these two effects. In the particular case where $g(j)=0, \forall j \in[0, N]$, market coverage is strictly lower (Proposition 3).

These conclusions echo those of Valletti, Hoernig, and Barros (2002), who consider a similar problem but with a focus on the "market sharing" pure strategy equilibrium. ${ }^{6}$ As we have just shown, this equilibrium might not be a valid candidate in the Hotelling context. In the next section we attempt to generalize the approach. In particular, we study how the existence of the market sharing pure strategy equilibrium depends on the degree of product differentiation and on the entrant's coverage.

\section{Existence of a pure strategy equilibrium: The general case}

We assume that firm $I$ and $E$ sell differentiated products; they compete simultaneously in prices, taking $n_{e}>0$ as given. Production costs are normalized to zero. $x_{k}^{D}\left(p_{i}, p_{e}\right)$ and $x^{M}(p)$ are assumed to be well behaved. In particular, there exists a unique well-defined monopoly solution and, in case of duopoly, goods are demand substitutes.

Define

$$
p^{m} \equiv \underset{p}{\operatorname{argmax}} \pi^{M}(p)
$$

${ }^{6}$ The only qualitative difference with their paper pertains to the evolution of the price on the insulated markets that unambiguously decreases in the market sharing equilibrium but not in the other two equilibrium configurations. 


$$
\phi_{k}^{1}\left(p_{j}\right) \equiv \underset{p_{k}}{\operatorname{argmax}} \pi_{k}^{D}\left(p_{k}, p_{j}\right)
$$

Without universal service obligations, the monopoly price $p^{m}$ prevails on the insulated markets and equilibrium prices $\left(p_{i}^{1 *}, p_{e}^{1 *}\right)$ apply on the contested markets.

With universal service obligations, firm I's MinMax payoff is equal to $\left(N-n_{e}\right) \pi^{M}\left(p^{m}\right)$. Let us then denote by $\hat{p}_{i}\left(p_{e}\right)$ the solution to equation $x_{i}^{D}\left(\hat{p}_{i}, p_{e}\right)=0$; that is, $\hat{p}_{i}\left(p_{e}\right)$ defines the critical price above which the incumbent faces no demand on the contested markets. Then, given $p_{e}$, the payoff of the incumbent is formally defined by:

$$
\Pi_{i}\left(p_{i}, p_{e}\right)=\left\{\begin{array}{ll}
\left(N-n_{e}\right) \pi^{M}\left(p_{i}\right)+n_{e} \pi_{i}^{D}\left(p_{i}, p_{e}\right) & \text { if } p_{i} \leq \hat{p}_{i}\left(p_{e}\right) \\
\left(N-n_{e}\right) \pi^{M}\left(p_{i}\right) & \text { if } p_{i} \geq \hat{p}_{i}\left(p_{e}\right)
\end{array} .\right.
$$

There are two local maximizers:

- $\phi_{i}($.$) along the first branch of (15) and$

- $p^{m}$ along the second branch of (15).

The extent to which the first maximizer dominates the second one obviously depends on the extent of market coverage; that is, on $n_{e}$. More fundamentally, the lack of concavity is likely to destroy the existence of a pure strategy equilibrium. Notice that a sufficient condition ensuring that this lack of concavity is not problematic consists in assuming that $x_{i}^{D}\left(p^{m}, 0\right)>0$. In this case, the non-negativity constraint cannot be binding in the relevant domain of prices because firm $I$ will never quote a price above the monopoly price while firm $E$ will not sell at a loss. ${ }^{7}$

To characterize firm I's best reply, we must compare the payoffs along the two profiles:

$$
n_{e} \pi_{i}^{D}\left(\phi_{i}\left(p_{e}\right), p_{e}\right)+\left(N-n_{e}\right) \pi^{M}\left(\phi_{i}\left(p_{e}\right)\right)=\left(N-n_{e}\right) \pi^{M}\left(p^{m}\right)
$$

which can be rewritten as follows:

$$
\frac{n_{e}}{N-n_{e}} \pi_{i}^{D}\left(\phi_{i}\left(p_{e}\right), p_{e}\right)+\pi^{M}\left(\phi_{i}\left(p_{e}\right)\right)=\pi^{M}\left(p^{m}\right) .
$$

Because of strategic complementarity, the left-hand side of the equation is continuous and strictly increasing in $p_{e}$ in the relevant domain, whereas the right-hand side is constant. Moreover, $\pi^{M}\left(\phi_{i}\right) \leq \pi^{M}\left(p^{m}\right)$. Accordingly, there exists at most one solution to the above equation. Let us denote this solution by $\tilde{p}_{e}$. The incumbent's best reply correspondence, therefore, writes as follows:

$$
B R_{i}\left(p_{e}\right)=\left\{\begin{array}{ll}
p^{m} & \text { if } p_{e} \leq \tilde{p}_{e} \\
\phi_{i}\left(p_{e}\right) & \text { if } p_{e} \geq \tilde{p}_{e}
\end{array} .\right.
$$

Because $p^{m}>\phi_{i}\left(\tilde{p}_{e}\right)$, the best reply correspondence exhibits a downward discontinuity at $\tilde{p}_{e}$.

7 Valletti, Hoernig, and Barros (2002) implicitly assume that this condition is satisfied, which indeed can be interpreted as putting a lower bound on the degree of product differentiation. 
As for the entrant's behavior, two strategy profiles are a priori possible. The entrant can either compete with the incumbent on all contested markets or choose to quote a limit price. The first strategy corresponds to $p_{e}=\phi_{e}^{1}\left(p_{i}\right)$ and the second one to a limit price $p_{e}^{L}$ defined as the solution of $x_{i}^{D}\left(p_{i}, p_{e}\right)=0$. The second strategy applies whenever the non-negativity constraint is binding for firm $I$ at prices $\phi_{e}^{1}\left(p_{i}\right)$. Therefore, the entrant's best reply function is kinked and defined as:

$$
B R_{e}\left(p_{i}\right)=\operatorname{Max}\left[\phi_{e}^{1}\left(p_{i}\right), p_{e}^{L}\left(p_{i}\right)\right] .
$$

There are a priori two pure strategy equilibrium candidates: the market sharing pure strategy equilibrium and the quasi-monopoly pure strategy equilibrium. It is immediate to establish that the second candidate can be ruled out whenever the equilibrium monopoly price is interior; that is, whenever the monopoly payoff function is differentiable at $p^{m} \cdot{ }^{8}$ In this case, at $p^{m}$, the derivative of the payoffs on the insulated markets is zero, whereas it is strictly negative on the contested ones. As a consequence, firm I's best reply must be $\phi_{i}\left(p_{e}^{L}\right)$. We are then left with a unique interior pure strategy equilibrium candidate. Because firm I's best reply is discontinuous, this equilibrium might not be a valid candidate either. Lemma 3 summarizes the structure of the price equilibrium under universal service obligations. The first part of Lemma 3 (non-existence of a pure strategy equilibrium) follows from the discontinuity in I's best reply, whereas the second part (existence of a mixed strategy equilibrium) follows from the payoffs' continuity (Glicksberg 1952).

Lemma 3 Whenever $p_{e}^{*}<\tilde{p}_{e}$ the Market Sharing Pure Strategy Equilibrium does not exist. When this equilibrium does not exist, there always exists a mixed strategy equilibrium.

Moreover, average prices in a mixed strategy equilibrium are strictly above the pure strategy ones. Having described the structure of the price equilibrium, we now concentrate on the economic conditions under which the market sharing pure strategy equilibrium exists. This question is prompted by Valletti, Hoernig, and Barros (2002) who exclusively focus on that equilibrium. The answer depends on the entrant's market coverage and the degree of product differentiation. When products are sufficiently differentiated, the pure strategy equilibrium exists (Valletti, Hoernig, and Barros 2002; Hoernig 2006) while, for homogenous products, the unique equilibrium is the mixed strategy equilibrium whenever the incumbent has a strictly positive MinMax payoff (Hoernig 2002).

Let us measure product differentiation by a parameter $\delta \in[\underline{\delta}, \bar{\delta}]$. The lower bound corresponds to homogeneous products and the higher bound to independent demands. We already established that a pure strategy equilibrium always exists whenever $x_{i}^{D}\left(p^{m}, 0\right)>0$, which implicitly defines a bound on $\delta$ above which existence is nonproblematic. The following proposition characterizes the type of equilibrium prevailing for each possible value of $\delta$ and $n_{e}$.

Proposition 4 (i) For each $n_{e} \in(0, N)$, there exists a degree of product differentiation $\tilde{\delta}<\bar{\delta}$ such that for $\delta \leq \tilde{\delta}$, the Market Sharing Pure Strategy Equilibrium fails to exist. (ii) $\tilde{\delta}$ is decreasing in $n_{e}$.

8 This condition is not satisfied in the Hotelling setup developed in the previous section. 


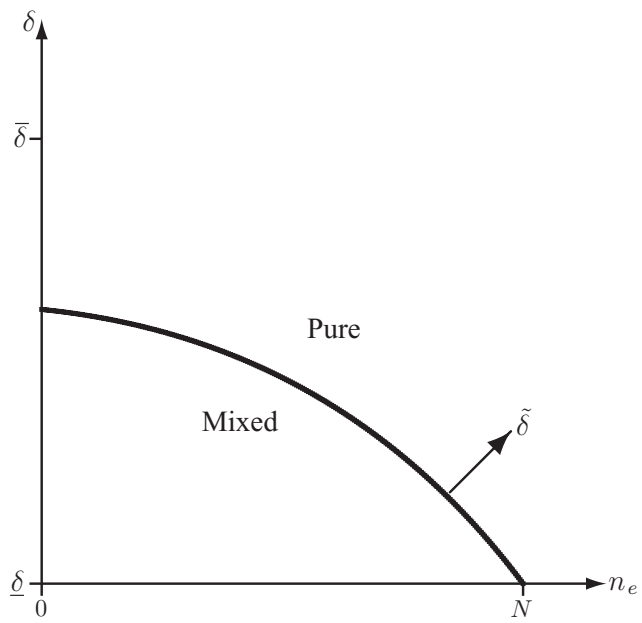

Figure 4 Equilibrium type in the price game.

Proof: The pure strategy equilibrium fails to exist whenever $p_{e}^{*} \leq \tilde{p}_{e}$. Consider any given $n_{e} \in(0, N)$. When the degree of product differentiation, $\delta$, varies, the equilibrium and the cut-off prices vary in opposite directions: $\frac{\partial p_{e}^{*}}{\partial \delta}>0$ and $\frac{\partial \tilde{p}_{e}}{\partial \delta}<0$. Moreover, when products are almost homogeneous, we have $p_{e}^{*}<\tilde{p}_{e}: \lim _{\delta \rightarrow \underline{\delta}} p_{e}^{*}=0$ and $\lim _{\delta \rightarrow \underline{\delta}} \tilde{p}_{e}>0$. Combined with the fact that whenever $x_{i}^{D}\left(p^{m}, 0\right)>0$ the corresponding equilibrium is the pure strategy equilibrium, we have proven part (i).

We have thus identified a locus $\tilde{\delta}\left(n_{e}\right)$ characterized by $p_{e}^{*}\left(\tilde{\delta}\left(n_{e}\right), n_{e}\right)=\tilde{p}_{e}\left(\tilde{\delta}\left(n_{e}\right), n_{e}\right)$. For a given $\delta$, when $n_{e}>\tilde{\delta}^{-1}\left(n_{e}\right)$, the corresponding equilibrium is the pure strategy equilibrium. As a matter of fact, both $p_{e}^{*}$ and $\tilde{p}_{e}$ are decreasing in $n_{e}$ and $\left.\lim _{n_{e} \rightarrow N} p_{e}^{*}=p_{e}^{* 1}>\lim _{n_{e} \rightarrow N} \tilde{p}_{e}=p_{e}^{L}\left(p^{m}\right)\right)$. Therefore, for a given $\delta$, the mixed strategy equilibrium applies for the lowest coverage and the pure strategy equilibrium for the highest coverage. This proves that the locus $\tilde{\delta}\left(n_{e}\right)$ is decreasing in $n_{e}$.

Proposition 4 associates to all possible degrees of product differentiation and possible coverages the corresponding equilibrium type in the price game. Figure 4 illustrates the proposition. The pure strategy equilibrium does not exist when the incumbent's MinMax payoff is high (low coverage by the entrant) and when competition is fierce (little product differentiation). In addition, when the coverage increases (and, therefore, the incumbent's MinMax payoff decreases), it is possible to sustain the pure strategy equilibrium for more homogeneous products.

\section{Final remarks}

In this paper, we have analyzed the impact of universal service obligations on the intensity of price competition and on the extent of market coverage by the entrant. Previous papers, most notably Valletti, Hoernig, and Barros (2002), emphasize the strategic link that results 
from the imposition of universal service obligations on the incumbent firm: universal service obligations weaken price competition because they penalize the incumbent from fighting in the contested markets through the monopoly revenues lost on the protected markets. The entrant, in turn, might benefit from this strategic link by controlling for the incumbent's aggressiveness through its own choice of market coverage. We push this intuition to its end by showing that, under low market coverage, the willingness to retreat in the protected markets actually leads to the non-existence of an equilibrium (in pure strategies). ${ }^{9}$ We show that this problem is almost a generic one: whatever the extent of market coverage, there exist products' characteristics for which the non-existence problem arises. We also show that in a mixed strategy equilibrium, prices are higher, on average. As a consequence, neglecting the existence of these mixed strategy equilibrium amounts to underestimate the anticompetitive consequences of universal service obligations.

Universal service obligations typically constrain the incumbent to offer its products for sale in all segments of the market. Obviously, however, it may happen that the price differential is so large that the incumbent faces no demand at all on the contested markets. In any industry where such a configuration makes sense, our analysis is relevant. Such market configurations are expected to prevail with homogeneous products, for vertically differentiated products and horizontal products. ${ }^{10}$ Moreover, the example we develop, based on a Hotelling framework, relies on a unit demand setup. This setup essentially describes a market where consumers rely on a unique provider, in which they possibly buy several units; that is, a market where benefiting from the service requires a form of affiliation and where there is no real benefit to be obtained from being registered to multiple service providers. Needless to say, this is a reasonable description of markets for postal services, energy provision and telecoms, for instance. These models are the most prone to generate the "higher price" mixed strategy equilibrium we identify as a consequence of universal service obligations.

\section{References}

Anton, J., J. Vander Weide, and N. Vettas (2002), "Entry auctions and strategic behavior under cross-market price constraints," International Journal of Industrial Organization 20, 611-29.

Armstrong, M. (2008), "Access pricing, bypass and universal service in post," Review of Network Economics 7, 172-87.

Boccard, N., and X. Wauthy (2003), "Export restraints and horizontal differentiation,” Japanese Economic Review 54, 395-408.

Choné, P., L. Flochel, and A. Perrot (2002), "Allocating and funding universal service obligations in a competitive market," International Journal of Industrial Organization 20, 1247-76.

Glicksberg, I. L. (1952), "A further generalization of the Kakutani fixed-point theorem with applications to Nash equilibrium points," Proceedings of the American Mathematical Society 3, 170-74.

Hoernig, S. (2002), "Should uniform pricing constraints be imposed on entrants?," CEPR Working Paper, CEPR, London.

9 A noticeable exception is Hoernig (2002), who addresses the problem in the particular case of homogeneous goods.

10 Armstrong (2008) develops such a stylized model where the incumbent may loose all its clients in one region after market opening. 
Hoernig, S. (2006), “Should uniform pricing constraints be imposed on entrants?," Journal of Regulatory Economics $30,199-216$.

Krishna, K. (1989), “Trade restrictions as facilitating practices," Journal of International Economics 26, 251-70.

Mirabel, F., J.-C. Poudou, and M. Roland (2009), "Universal service obligations: The role of subsidization schemes," Information Economics and Policy 21, 1-9.

Panzar, J. (2000), “A methodology for measuring the costs of universal service obligations," Information Economics and Policy 12, 211-20.

Valletti, T., S. Hoernig, and P. Barros (2002), "Universal service and entry: The role of uniform pricing and coverage constraints," Journal of Regulatory Economics 21, 169-90. 